\title{
A ambivalência da técnica e da tecnologia na profissionalização do ensino médio
}

\author{
José Deribaldo Gomes dos Santos \\ Ellen Cristine dos Santos Ribeiro \\ Thiago Chaves Sabino Correio
}

Universidade Estadual do Ceará

\section{Resumo}

A proposta do artigo consiste em situar o papel da técnica e da tecnologia dentro da chamada "era tecnológica", discutindo as facetas atribuídas a essas categorias. A apropriação desses conceitos permite uma abordagem mais consistente da profissionalização do ensino médio, que ocorre de forma cada vez mais precoce. Encerramos esta comunicação com a discussão sobre a dualidade educativa que a profissionalização do ensino médio encobre e que tem se consolidado nas esferas profissional e propedêutica, pública e privada.

Palavras-chave: Técnica. Tecnologia. Educação Profissional. Ensino Médio. 


\section{La ambivalencia de la técnica y la tecnología en el debate de la escuela secundaria}

\section{Resumen}

El propósito de este artículo es definir el papel de la técnica y tecnología dentro de la llamada "era tecnológica", discutiendo las facetas asignadas a estas categorías, valorándolos para el logro de la emancipación humana. La apropiación de estos conceptos permite un enfoque más coherente a la profesionalización de la escuela secundaria, que se hace cada vez más temprano. Se examina cómo, a partir de este punto de la revolución técnica-científica, la ciencia se ha transformado en una mercancía, el que se ajusta mejor a las inmediatas necesidades del capital, desarrollada por la demanda capitalista como cualquier otro elemento con fines comerciales. Cerramos esta comunicación con la discusión de la dualidad educativa que la profesionalización temprana de la escuela secundaria esconde y que se ha consolidado en el ámbito profesional y propedéutico, público y privado.

Palabras clave: Técnica. Tecnología. Educación Laboral. Escuela Secundaria.

\section{The ambivalence of technique and technology within the high school professionalisation speech}

\section{Abstract}

The purpose of the article is to define the role of technique and technology within the call "technological age", discussing the facets assigned to these categories, valuing them for the achievement of human emancipation. The appropriation of these concepts allows for a more consistent approach to high school professionalisation, which occurs increasingly early way. It examines how, from this landmark scientifictechnical revolution, science has been transformed into a commodity, making it less possible and more adjusted to the immediate capital needs, driven by capitalist demand as any other commercial purpose item. We conclude the communication with the discussion of covert functions contention that high school professionalisation covers, a fact that has consolidated the educational duality in professional spheres and workup, public and private.

Keywords: Technique. Technology. Professional education. High school. 


\section{Ambivalence de la technique et de la technologie dans l'enseignement secondaire professionnel}

\section{Résumé}

L'objectif de l'article est définir le rôle des techniques et de la technologie au sein de l'appel "ère technologique", en discutant les facettes assignées à ces catégories. L'appropriation de ces concepts permet une approche plus cohérente à la professionnalisation de l'école secondaire, qui se produit à une forme de temps auparavant. Nous fermons cette communication avec la discussion de la dualité éducative que la professionnalisation des couvertures du secondaire et qui a été consolidée dans les sphères professionnelles et propédeutique, publics et privés.

Mots-clés: Technique. Technologie. Formation professionnelle. École Secondaire.

\section{Introdução}

A presente comunicação pretende alargar a compreensão dos conceitos de técnica e de tecnologia como fatores de propulsão para a emancipação humana. Nesse debate, empreendemos a discussão das facetas redentora e malévola, para, a partir desse ponto, entender que precisar essas categorias é indispensável para a compreensão das determinações responsáveis pela subordinação cultural e econômica dos países que estão situados na periferia do capital. Em particular, procura-se, com este artigo, apresentar uma crítica ao conceito de "era tecnológica" revestido do arcabouço ideológico burguês interessado em obscurecer a realidade. Deste problema, discute-se como as definições equivocadas de técnica e tecnologia influenciam o currículo da Educação Profissional (EP) que hoje recebe orientação oficial de voltar-se à integração com o Ensino Médio (EM), acompanhada de um apelo ideológico-econômico para a profissionalização do ensino.

Para dar conta desses objetivos, a comunicação priorizou um estudo de caráter teórico, bibliográfico e documental. Partiu-se do contexto histórico que impõe fortes transformações na base do capitalismo, ocorridas, principalmente, a partir da década de 1970 que demanda, por seu turno, uma comemorada revolução técnicocientífica. A investigação se valeu do arcabouço teórico-metodológico proposto por autores notadamente marxistas, optando pelo diálogo, em primeiro plano, com as interpretações de Vieira Pinto (2008), Braverman (1980), entre outros autores. 


\section{A educação no contexto da chamada era tecnológica: pontuando o debate}

O primado da técnica não deve ser endeusado nem repudiado, mas analisado criticamente sobre bases filosóficas consistentes, de modo a situar seu papel no desenvolvimento histórico da humanidade. O filósofo Álvaro Vieira Pinto (2008) enfatiza que a filosofia da técnica precisa estar baseada no entendimento da relação homem e natureza, contextualizada no modo de produção da sociedade, fundamentada na perspectiva do materialismo dialético.

A partir da categorização da técnica e da tecnologia, prossegue Vieira Pinto, produziuse intencionalmente e/ou ingenuamente uma conexão de fatores que servem de base de sustentação a um apanhado de concepções teóricas ludibriantes que encobrem o cenário de profunda barbárie social. Tais misticismos conceituais pretendem, ao fim e ao cabo, encobrir as precípuas consequências da crise capitalista, além de comporem e difundirem o arcabouço ideológico responsável por inserir o cotidiano do trabalhador nesse emaranhado apologético de deturpação dessas duas categorias.

Braverman (1980) considera que gerenciar o processo produtivo proporciona estrutura formal, mas tal processo jamais estaria completo sem seu conteúdo, que é uma questão de técnica. Assinala que a técnica parte da especialidade, do ofício, para depois assumir um caráter cada vez mais científico à medida que "o conhecimento das leis naturais aumenta e destitui o conhecimento fragmentado e as tradições fixas do ofício" (Braverman, 1980, p. 137).

Voltando a Vieira Pinto (2008), esclarecemos que o temor de submeter o homem à técnica constitui verdadeiro engano, visto que ambos estão determinados por uma relação recíproca. Conquanto, o receio de sujeitar a vida humana à técnica não se determina nela em si, mas no regime social estabelecido, que revela uma visão simplista e reduzida desta categoria. No entendimento de Sousa Júnior, é fundamental compreender inicialmente que

[...] não parece razoável supervalorizar o potencial emancipador da tecnologia da indústria moderna pelo simples fato de que representa nível de qualificação superior às formas de trabalho pré-modernas. Esse entendimento mesmo, via de regra, tende a apagar a contradição própria de todo avanço tecnológico e científico no mundo das mercadorias que é justamente a dimensão imanente da desqualificação e da degradação do trabalho. (Sousa Júnior, 2010, p. 93)

Em linhas gerais, a ambivalência da tecnologia "demonstra-se muito apropriada para dar-Ihe a aparência de divindade transcendente" (Vieira Pinto, 2008, p. 291). Já Santos (2012), aponta que a história se encarregou de registrar a maneira como alguns 
povos se desenvolveram através da espoliação, pilhagem, genocídio, dentre outras práticas brutais de acumulação. Nos marcos do capitalismo monopolista e da crise crônica do capital contemporâneo, essa evolução deixou importante herança e ainda contribui com o alarmante desnível de acúmulo de técnicas e tecnologias entre os países situados no centro e na periferia do capitalismo, numa curva que ainda está na crescente. Contrariamente, avistamos a tecnologia na perspectiva de Vieira Pinto (2008, p. 269) como algo que deveria "ser, por necessidade, patrimônio da espécie" humana.

A tecnologia em si não guarda o cerne do bem ou do mal, pois se trata de uma condição para a evolução do homem, para a emancipação plena da humanidade. As máquinas construídas pelo trabalho do ser social não têm o poder de, por si só, promoverem a atual precarização social agudizada pela era do capital, não há carga moral nela, boa ou má. A essência do problema reside no emprego que se faz da tecnologia, sobretudo, na aplicação das possibilidades que o maquinário coloca a serviço do capital: garantir o acúmulo do lucro para uma privilegiada parcela da população mundial (Santos, 2012).

Sobre as facetas malévola e redentora assumidas pela tecnologia nos tempos atuais, Vieira Pinto (2008) argumenta que alguns literatos e filósofos, debruçados sobre a filosofia da técnica, se utilizam de sofisticados argumentos para fazer apologia ao que acreditam ser a "sociedade do conhecimento" ou, sob outras alcunhas não menos sedutoras, conforme relembra Santos (2012), como: era tecnológica, da informação, dentre outras.

A expressão "era tecnológica", em seu sentido ontológico, designa toda a época da evolução humana em que o homem age sobre a natureza a partir das técnicas disponíveis para satisfazer contradições existentes entre ele e o meio natural. Todas as eras foram tecnológicas, pois, em seu próprio tempo, expressaram o apogeu da evolução técnica humana. A tecnologia é um fator de propulsão do homem e "supor o contrário, seria imaginar que a história se repita, estacione ou corra para trás; o homem jamais seria humanizado se não fosse tecnológico" (Vieira Pinto, 2008, p. 47). O homem, distanciado do mundo devido à privação da prática de transformação material da realidade e do estranhamento com o produto de seu trabalho, perdeu, pouco a pouco, a noção de ser ele próprio o autor de suas obras, acreditando estar situado numa era privilegiada em relação às demais. Santos, inspirado em Vieira Pinto, desconstrói esta falácia. Para ele:

A expressão "era tecnológica", em seu sentido onto-histórico, apenas serve para evocar toda época da evolução humana onde o homem age sobre a natureza com as técnicas que dispõe para solucionar as contradições existentes entre ele e o meio natural. Isto é, quando o sujeito utiliza as propriedades dos corpos, as forças naturais desantropomorfizadas que existem independente de sua vontade, como forma de fortalecer o rendimento de seu trabalho sobre os objetos naturais que recebem sua ação. (Santos, 2012, p. 51) 
Se, em termos filosóficos, como entende Viera Pinto (2008, 175-8), "[...] o ato [técnica] realiza, enquanto mediação, o fim intencional do agente, é a mediação na obtenção de uma finalidade humana consciente", a técnica só pode ser avaliada e classificada em boa ou ruim quando correlacionada às suas finalidades. Para o autor, só é possível estudar a técnica se posicioná-la em seu logos: a tecnologia. Portanto, o emprego que se faz da tecnologia é onde se deve "procurar o cerne da questão, sobretudo, na aplicação das possibilidades que o maquinário coloca a serviço do capital: garantir o acúmulo do lucro para uma privilegiada parcela da população mundial" (Santos, 2013, p. 70).

Constitui-se grande equívoco justificar o problema da pobreza no desnivelamento da tecnologia entre países, pois o conjunto de mazelas sociais experimentadas pela humanidade é justificado, em essência, pela estrutura que a rege. O princípio da desigualdade caminha lado a lado com os pressupostos do modelo opressor do capital, não da tecnologia, elemento fundamental para a emancipação humana.

Com base nos estudos de Rüdiger (2005) sobre o legado de Vieira Pinto, pode-se ler que, de um lado, os tecnocratas futuristas celebram a técnica e a tecnologia com o intuito de impedir sua apropriação autônoma ou obstaculizar seu desenvolvimento por parte dos países de capitalismo periférico. De outro lado, os humanistas retrógrados reprovam essas duas categorias pelas mesmas razões, embora de modo inverso, pois elogiam os estágios mais atrasados de vida social, o que certifica o caráter apocalíptico do desenvolvimento tecnológico. A tecnologia, no cenário da chamada "era tecnológica", sofre dois ataques frontais: por um lado é percebida como demoníaca e, por outro, como salvadora de todos os males da humanidade, principalmente para os países que orbitam na periferia do capitalismo. Ambas as posições se equivocam exatamente por não levarem em conta a relação produtiva que o ser social mantém com a natureza e com a sociedade. Como delineia Romero:

No capitalismo, a técnica não é apenas um instrumento do processo de trabalho, como ocorria nas formações sociais pré-capitalistas, mas um instrumento do processo de valorização, implicando e determinando uma relação específica de domínio e de exploração do trabalhador. (Romero, 2005, p. 124)

Mas por que então tanta fantasia nas análises da técnica e da tecnologia? Com base nas investigações de Vieira Pinto (2008), ousamos indicar que o caráter mistificador implantado em torno dessas duas categorias é de grande valia para justificar as políticas educacionais que elegem o ensino profissionalizante como principal alternativa aos filhos dos trabalhadores. Desconstruir a idolatria vinculada à suposta "era tecnológica" permite desmontar o arcabouço ideológico que a reveste, de modo a denunciar as refinadas táticas de controle daqueles que o filósofo brasileiro nomeou de "grandes conglomerados capitalistas".

Quartiero, Lunardi e Bianchetti (2010, p. 286) examinam como esses dois conceitos 
têm sido empregados nas instituições escolares por meio dos documentos oficiais que propõem e definem as políticas curriculares para o sistema educacional brasileiro. Para esses autores, as prescrições curriculares, em especial as que estão presentes nas Diretrizes Curriculares Nacionais para o Ensino Médio (1998) e nas Diretrizes Curriculares Nacionais para a Educação Profissional de Nível Técnico (2000), "não representam um texto homogêneo ou articulado aos interesses de um único grupo de profissionais, pensadores e responsáveis pela implementação das políticas educacionais"; na verdade, trata-se de documentos produzidos "no embate entre diferentes perspectivas e, portanto, representa as tensões existentes no campo da educação no momento de sua elaboração e processo de implementação" (Quartiero; Lunardi; Bianchetti, 2010, p. 286).

A apropriação histórica dos conceitos de técnica e tecnologia parte, de maneira geral, de dois pressupostos: 1) a ativa vinculação da escola, em sua forma institucional, aos diferentes modos de produção numa relação histórica entre a instituição escolar e os sistemas produtivos; 2) a utilização e preservação - na educação e, em especial, na educação profissional - da norma que enaltece a contínua mudança tecnológica, o que reitera os discursos de valorização da chamada "era tecnológica", fortalecendo uma suposta neutralidade da tecnologia, além de uma lógica pragmática e utilitarista (Quartiero; Lunardi; Bianchettil, 2010).

A necessidade apontada por Quartiero, Lunardi e Bianchetti (2010, p. 286) de (re) conceitualizar a tecnologia se alinha a um dos objetivos por nós delineados para o presente estudo, na medida em que se constata existir, na educação escolar em si, a expressão de algumas tecnologias, sejam elas simbólicas, organizacionais ou instrumentais, o que, tomadas por inovações pedagógicas, impõem a revisão constante das competências e concepções correntes na escola. Conforme a categorização dos referidos autores, as tecnologias incorporadas à educação escolar são: simbólicas inventadas (linguagem, representações icônicas, saberes escolares), tecnologias organizacionais (gestão, arquitetura escolar, disciplina) e tecnologias instrumentais (quadro-verde, giz, televisão, vídeo, computador).

Com a tematização da ambivalência assumida pela técnica/tecnologia e sua aplicação no contexto escolar aclarada, agora torna-se necessário discutir a chamada revolução técnico-científica e sua relação com a profissionalização do ensino médio, problematização que será enfrentada a seguir. 


\section{Revolução técnico-científica e profissionalização do Ensino Médio: aspectos críticos e relação com o contexto atual}

Braverman (1980) aponta que a ciência - depois do trabalho - é a última e mais importante propriedade social a converter-se num facilitador do capital. A incorporação da ciência às organizações capitalistas justifica a conversão dos pesquisadores quase amadores para o estado atual, altamente organizado e perdulariamente financiado. A aplicação persistente da técnica e da ciência no processo produtivo - a fim de renovar constantemente o estágio tecnológico da sociedade - é requisito fundamental para a ordem do capitalismo. Se o princípio regente deste modo de produção é a acumulação, a gerência científica exerce um papel fundamental nas transformações funcionais e estruturais da produção e da classe trabalhadora.

Reconhece o autor, entretanto, a existência de uma quantidade jamais vista de conhecimentos científicos incorporados aos processos produtivos, o que gera a necessidade de qualificar/requalificar o trabalhador a fim de que ele possa "acompanhar" as evoluções tecnológicas associadas à produção. Perante o crescente desenvolvimento das tecnologias e sua absorção no processo produtivo, o capitalismo demanda que o trabalhador submeta-se, continuamente, à qualificação, requalificação e atualização de suas habilidades para melhor operar a produção. Examinando os rumos tomados por essa trajetória, verificamos que, caso essa formação não ocorra, o processo de valorização do capital, em termos absolutos ou relativos, fica comprometido.

Conforme debate Braverman (1980), a massa trabalhadora nada tem a ganhar com o fato do declínio de seu comando sobre o processo de trabalho estar compensado pelo comando crescente por parte dos gerentes e engenheiros. Ao contrário, sua qualificação decai em sentido absoluto (com a perda do ofício e das capacitações tradicionais jamais compensadas) e, em maior medida, em sentido relativo.

Vieira Pinto (2008, p. 170) confronta analiticamente a propagação da imagem da "era tecnológica" ao afirmar que, ao contrário, trata-se de um mergulho no provincianismo próprio da consciência ingênua: "o laboratório de pesquisas, anexo à gigantesca fábrica, tem o mesmo significado ético da capelinha outrora obrigatoriamente exigida ao lado dos nossos engenhos rurais". O filósofo demonstra que o dano mais grave causado pela desigualdade entre países desenvolvidos e os de desenvolvimento capitalista precário é a propagação da crença de que grandes problemas são forçosamente resultado da falta de eficiência na gestão e da escassez de instrumentos adequados e assevera em tom austero: "contra esta errônea e insidiosa uniformização é que nos pronunciamos" (Vieira Pinto, 2008, p. 170). 
Para fins de clareza, Braverman (1980) faz a devida distinção entre revolução técnico-científica e Revolução Industrial. Nesta última, em contraste com a prática moderna, a ciência não tomou rigorosamente a dianteira da indústria, formulando suas generalizações na marcação do desenvolvimento tecnológico ou em consequência dele. $\mathrm{O}$ avanço científico entre os séculos XVI e XVII viabilizou as condições para a Revolução Industrial, mesmo de forma indireta e difusa, pois, se por um lado, a ciência ainda não estava estruturada diretamente pelo capitalismo, por outro, "a técnica desenvolveu-se antes e como um requisito prévio para a ciência" (Braverman, 1980, p. 138).

No período do capitalismo nascente, o andamento da tecnologia caracterizou-se de modo intrínseco ao processo produtivo, extraindo maturação científica a partir da evolução concreta da indústria. A revolução de que nos fala Braverman (1980) está fundamentada na incorporação da ciência ao capital, transformando os fins científicos nos próprios fins do capital. Esta análise é robustecida pelo autor, na medida em que constata que a ciência tem sido empregada, através dos tempos, "como fio cortante da transformação industrial" (Braverman, 1980, p. 140).

Diante da investigação do reabastecimento das possibilidades tecnológicas a partir da chamada revolução técnico-científica, bem como da transformação da ciência em mercadoria ajustada à lógica do mercado, precisamos agora adentrar, especificamente, na apreciação crítica da educação profissional. Relembramos com Santos o complexo de determinações que posicionam o Brasil no mapa do mundo batizado de globalizado, que condiciona os países periféricos a comprar artefatos tecnológicos advindos dos países centrais:

Desprovido dos elementos que favoreçam uma análise devidamente contextualizada do real, capaz de radicar o desenvolvimento da ciência e da tecnologia no plano das necessidades, vinculadas ao complexo do trabalho através de uma teia de infindas mediações, resta ao MEC e a seus gentis intelectuais insistir na crença, praticamente religiosa, do desenvolvimento tecnológico como determinação central da sociabilidade atual, o que caracteriza um ufanismo tecnológico míope e apologético [...]. (Santos, 2012, p. 127)

O que esse autor aponta é que uma leitura mais atenta dos documentos oficiais - aqui, em especial, o Conselho Nacional de Educação (CNE) de 2002 - põe à vista que, para o MEC, conforme se indicou acima nas reflexões de Quartiero, Lunardi e Bianchetti (2010), o desenvolvimento da ciência e da tecnologia protagoniza transformações autônomas e, ao passo que supõe haver neutralidade nessa esfera, despreza as experiências sociais ou, em relação à produção, para além das vontades e conflitos humanos, novos problemas e desafios. Destarte, os cursos aligeirados, rasteiros e conciliados à lógica mercadológica sequer mereciam levar o estandarte dos chamados cursos técnicos, tamanha é a deturpação de tal categoria - já na nomenclatura. 
debate da educação profissional - travado por integrantes de várias linhas de pensamento - sempre foi um ponto tenso de incongruência na educação, representando, em última análise, as determinações da postura do Estado quanto ao reforço do dualismo educacional, num caminho marcado por inúmeras tensões e polarizações. Por meio da discussão da proposta direcionada aos jovens de continuidade dos estudos e, ao mesmo tempo, de preparação para o chamado mundo do trabalho, o ensino médio carrega essa oscilação histórica entre ser profissionalizante, para uma classe, e preparatório para o ensino superior, para outra.

O EM público, sobretudo o noturno, ao longo da história, esteve voltado ao mercado de trabalho capitalista. Este ideário, segundo aborda Ramos (2010), vigorou plenamente durante o projeto nacional-desenvolvimentista, com a possibilidade ampla de emprego, cuja finalidade mister da educação passou a ser a preparação para o mercado de trabalho, tanto no ensino médio como no ensino superior. Tal projeto exibiu sua fragilidade a partir da "crise dos empregos e mediante um novo padrão de sociabilidade capitalista, caracterizado pela desregulamentação da economia e pela flexibilização das relações e dos direitos sociais" (Ramos, 2010, p. 47).

Num cenário de instabilidade empregatícia, canalizar a tônica da educação à preparação para o mercado de trabalho capitalista não fazia muito sentido, o que justificou a mudança do discurso oficial, a partir da LDB n 9.394/96, para a orientação do desenvolvimento de competências "genéricas e flexíveis, de modo que as pessoas pudessem se adaptar facilmente às incertezas do mundo contemporâneo" (Ramos, 2010, p. 47).

Ao se articular esse contexto com a problemática do Ensino Médio Integrado (EMI), que se espalha atualmente por todo o Brasil - impulsionado especialmente devido aos Decretos $n^{\circ}$ 5.154/04 e n 6.302/07 - ressaltamos que a função propedêutica da educação profissional não se efetivou ao longo dos anos e, na contramão, instaurouse uma espécie de apartheid educacional entre os filhos das classes intermediárias e dominantes e os filhos dos trabalhadores, afastando ambas as classes - mas de forma muito mais severa a menos favorecida - de uma formação ampla, baseada na consciência político-social e na compreensão da estrutura do sistema produtivo.

Em 2004, foi aprovado o Decreto no. 5.154. Esse instrumento legal, apesar de manter as ofertas dos chamados cursos técnicos nas formas concomitantes e subsequentes trazidas pelo Decreto ${ }^{\circ} 2.208 / 97$, retoma a possibilidade de integrar o nível médio à modalidade profissionalizante. No entanto, vale a pena conferir a seguinte crítica:

[...] O Decreto $n^{\circ}$ 5.145/04 não revoga o também Decreto $n^{\circ}$ 2.208/97. Após este dispositivo legal, fica aberta, decerto, a possibilidade da integração, no entanto o aligeiramento, a fragmentação, entre outras questões severamente criticadas no primeiro Decreto, permanecem no dispositivo que o sucede. Ademais, a nova legislação não impediu a desintegração. O que temos na atualidade é uma espécie de pode tudo: 
integração, o que apenas, naturalmente, pode se dar em uma mesma instituição; desintegração em dois momentos. Neste caso, o jovem precisa concluir o ensino médio em uma escola e, depois de conclui-lo, cursar o profissionalizante na mesma instituição ou em outra (também chamado de pós-médio, preferimos chamar de desintegração total); o outro caso, por fim, que denominamos de desintegração concomitante, ou seja, o estudante-trabalhador precisa fazer o ensino médio em uma escola e ao mesmo tempo cursar o profissionalizante em outra, ou na mesma instituição. (Santos; Farias; Freitas, 2013, p. 265)

Como se verifica nesta análise, a revogação da concepção enraizada no decreto de 1997 não acontece na prática, pois além da manutenção das antigas maneiras de funcionamento dos cursos técnicos (fragmentadas e meramente profissionalizantes), sua respectiva articulação/integração com o ensino médio regular não ocorre, na prática. Apenas existe a possibilidade de o estudante pleitear uma matrícula única em mesma instituição de ensino para dois cursos que ocorrem paralelamente e em turnos distintos. Para reforçar nossos argumentos, leia-se:

Reiteramos que a sobreposição de disciplinas consideradas de formação geral e de formação específica ao longo de um curso não é o mesmo que integração, assim como não o é a adição de um ano de estudos profissionais a três de ensino médio. (Frigotto; Ciavatta; Ramos, 2005, p. 1093)

Na década de 1990, Freitas (2011) utilizava o termo neotecnicismo para se referir ao conjunto de medidas engendradas pelo governo Fernando Henrique Cardoso, personificadas na figura do então ministro da educação Paulo Renato Costa Souza, e reconhece que tal orientação educacional já vinha sendo gestada desde o governo de Fernando Collor de Mello. Tal nomenclatura possui declarada referência à definição de "tecnicismo" elaborada por Saviani (2003) que, por sua vez, demarcava a investida liberal/conservadora das políticas voltadas à educação.

Compreende-se, então, que para a pedagogia tecnicista [...] marginalizado será o incompetente (no sentido técnico da palavra), isto é, o ineficiente e improdutivo. A educação estará contribuindo para superar o problema da marginalidade na medida em que formar indivíduos eficientes, portanto, capazes de dar sua parcela de contribuição para o aumento da produtividade da sociedade, Assim, ela estará cumprindo sua função de equalização social. Neste contexto histórico, a equalização social é identificada com equilíbrio do sistema. (Saviani, 2003, p. 13-14)

A análise conceitual de Saviani (2003) nos parece perfeitamente aplicável ao contexto adjetivado por Freitas (2011) de neotecnicista. De lá para cá, a trama vem se apresentando sob a forma de uma nova teoria da "responsabilização" e/ou da "meritocracia" combinada às várias formas de privatizações em que prevalecem a mesma racionalidade técnica de outrora. 
A respeito da centralidade empresarial de tal proposta, Freitas (2011, p. 4) relembra que a aprendizagem nesse enredo encontra-se mensurada por testes padronizados, que reforçam os processos de gerenciamento da força de trabalho na escola, como bônus, punições, perda de recursos e controle dos processos escolares, ancorados "nas mesmas concepções oriundas da psicologia behaviorista, da econometria, das ciências da informação e de sistemas, elevadas à condição de pilares da educação contemporânea". Essa cultura de auditoria está associada a uma gama de nomenclaturas oriundas das grandes corporações, conforme exemplifica Freitas (2011, p. 4): "qualidade assegurada", "transparência", "mérito", "melhores práticas", entre outras.

A despeito de um conceito mais abrangente de educação, os reformadores educacionais reduzem o entendimento de boa escola àquela em que os alunos atingem boas notas em português e matemática, rebaixando as outras disciplinas e ciências a um nível secundário enquanto elevam as habilidades cognitivas - um dos muitos aspectos humanos - ao ápice do desenvolvimento. Ainda mais grave, segundo o alerta de Freitas (2011, p. 5), é a admissão de boas notas ao conceito de boa educação. Boa parte dos países desenvolvidos tem dedicado esforços para competir qual é o melhor em português, matemática e ciências - comandada pela Organização para a Cooperação Econômica e Desenvolvimento - The Organisation for Economic Co-operation and Development (OCDE), e submetem este critério aos menos desenvolvidos.

Freitas (2011) advoga não ser democrático colocar a educação unicamente a serviço dos empresários, já que há mais agentes na sociedade. Nosso autor evoca o amplo debate em torno do projeto educativo destinado à juventude, lembrando que este não pode estar circunscrito à limitada objetividade dos testes:

A educação brasileira sofre e sofrerá nos próximos anos o assédio dos reformadores empresariais. Para eles, a educação é um subsistema do aparato produtivo e nisso se resume. Para os educadores profissionais, porém, formar para o trabalho é apenas parte das tarefas educacionais. E aí está uma divergência central. Para os reformadores empresariais, os objetivos da educação se resumem em uma "matriz de referência" para se elaborar um teste que mede habilidades ou competências básicas. Um país que não sabe o que pretende com sua juventude e que tudo que pode oferecer a ela como projeto de vida é passar no ENEM, não pode ir muito longe. (Freitas, 2011, p. 6)

Registramos, com Santos, Jimenez e Mendes Segundo (2011) que o contexto acima descrito vem, ao longo do tempo, mantendo sua vinculação ideológica com o projeto da classe dominante. Tomando as palavras de Vieira Pinto (2008, p. 41), arriscamos dizer "com valor de lei sociológica, que os serviçais em todos os tempos pensam analogamente". Aqui, é interessante refletir com Braverman (1980) que a educação se deteriora enquanto sua duração aumenta. Esse cenário favorece a possibilidade de que os empregadores utilizem o diploma como uma peneira para escolher os 
candidatos considerados mais aptos para profissões estratégicas na hierarquia de acumulação capitalista. A intensa concentração desses conhecimentos, ainda segundo esse autor, centralizada nas organizações de equipes associadas, impede o desenvolvimento das potencialidades da classe trabalhadora cuja oferta educativa a ela destinada tem por base a 'ressignificação' lancinante e inadequada do conceito de qualificação: "uma habilidade específica, uma operação limitada e repetitiva, a velocidade como qualificação" etc. (Braverman, 1980, p. 375).

Enfatizamos o arcabouço normativo posterior à promulgação da LDB n 9. 394/96 que constitui um compêndio de estratégias para reduzir a oferta do ensino médio profissionalizante a fim de privilegiar a educação modular e fragmentada (Santos, 2012). Entre outras consequências resultantes dessa leva de medidas, apontamos a ampliação das instituições privadas, amparadas no apoio financeiro estatal, o que estimulou a privatização endógena dos Centros Federais de Educação Tecnológica (CEFETs) e Escolas Técnicas Federais (ETFs), visto que os aproxima radicalmente do mercado, como afirma o Documento Políticas públicas para a educação profissional $e$ tecnológica (BRASIL; MEC; CNE, 2004). Este quadro transforma o ensino médio em verdadeiro funil, posto que sua oferta é prioritariamente pública, enquanto que o ensino superior tem a maioria de suas vagas na esfera privada.

Ademais, outro exemplo, fruto dessa mesma política, é confirmado pelo desmonte dos CEFETs e escolas técnicas federais com relação ao sistema de ensino integrado, formação geral/formação profissional, que se consolida através dos tempos, tornando-se uma experiência valiosa. Foi uma política imposta autoritariamente, sem que as instituições tivessem tempo para amadurecer os novos rumos possíveis, recursos e técnicas em suas instituições [...]. Dessa forma, a reforma encolhe o espaço público democrático dos direitos e amplia o espoco privado. (BRASIL; MEC; SEMTEC, 2004, p. 10-23)

Dessa referência, entretanto, é preciso extrair os limites de tais críticas, pois enquanto este documento censura as políticas educacionais do governo anterior de forma contundente, passa longe de indicar uma alternativa condizente com um real desenvolvimento econômico para o país e, contraditoriamente, aponta para a aproximação com as orientações dos organismos internacionais (Santos, 2012).

A conotação assumida pelo discurso oficial despreza a necessidade de apropriação do real na elaboração de uma crítica consistente ao governo antecessor, conduta emblemática para comprovar a superficialidade das políticas governistas neoliberais. Com efeito, o documento utiliza-se de um termo bastante atual no discurso acadêmico/oficial, a ressignificação, para ponderar sobre a importância da tecnologia nos currículos da educação profissional. Isto é, como se guardassem uma grande novidade teórica, propõem tratar a tecnologia "à luz de novos valores que vêm marcando o ser humano na sociedade contemporânea" (BRASIL; MEC; CNE, 2004, p. 12-3). 
Na medida em que acenam para o trabalhador com o aumento de uma suposta empregabilidade, as políticas governistas, independentemente de sua origem partidária e mesmo das diferenças entre si, coadunam-se com os interesses neoliberais que, por sua vez, resguardam as prerrogativas empresariais. Isso se evidencia nos artifícios utilizados para camuflar o desejo empresarial de atar a educação às demandas do capital.

O ajuste de um currículo ao gosto do mercado traz na ponta da língua um refinado rol de expressões indicando que o 'novo' empregado, tendo o verniz de adaptar a uma fantasiosa "era tecnológica", terá know-how para enfrentar o corrente quadro de crise-oportunidade gerado dentro do capitalismo. Especificamente no caso da provinciana elite brasileira, pretende-se "impor uma visão ideológica do ideal de novo empregado-cidadão em que o trabalhador é obrigado a se transmutar para sobreviver - via de regra, de forma precária - no contexto da crise hodierna" (Santos; Jimenez; Mendes Segundo, 2011, p. 33).

\section{Considerações finais}

A partir das mediações do legado marxista, o artigo procurou destacar as facetas malévola e benévola da técnica e da tecnologia dentro da chamada "era tecnológica", enfatizando, outrossim, o real dessas categorias na sociedade. A pesquisa procurou compatibilizar a necessária relação que técnica e tecnologia mantêm com o desenvolvimento das forças produtivas, bem como com as alterações nas relações sociais. Em tal contexto, a comunicação aponta que a chamada revolução técnicocientífica exige uma transformação da educação profissional (EP) e do ensino médio (EM), demandando para aquela modalidade educacional e para este nível de ensino novas orientações curriculares para uma adequação ao mercado de trabalho capitalista.

Em diálogo com as indicações de Braverman (1980) sobre o relacionamento entre escola, indústria capitalista e suas demandas, foi possível pontuar que apenas a partir da crise do capitalismo contemporâneo houve a necessidade iminente de o capital buscar novas apostas para gerenciar seus problemas, cenário fértil para que um novo epicentro curricular de modelo de formação do trabalhador fosse demandado pelas necessidades do capital.

A escola, como um espaço de construção de relações contraditórias, ocupada em consolidar a hegemonia dominante, mas com potencial, ao mesmo tempo de se tornar o locus capaz de fecundar uma possível superação, é fundamental na transição de conhecimentos para a organização das novas gerações. Por isso, a educação 
sistemática constitui um passo fundamental para um projeto de sociedade que atenda às classes subalternas.

Contudo, a "educação para o emprego/desemprego", reforçada ideologicamente pelo discurso da profissionalização em voga, produz verdadeiro vácuo na formação dos trabalhadores, reforçando a divisão social do trabalho e atravancando a aquisição de conhecimentos úteis e significativos às lutas dessa classe, cada vez mais distanciada da formação omnilateral defendida pelos clássicos do marxismo. Em outras palavras, a proposta educativa numa perspectiva ampliada que privilegia dimensões humanas como desenvolvimento da intelectualidade, da criatividade, da formação física do corpo, da afetividade, da compreensão estética sem fetiche etc., que precisam ser consideradas na formação humana integral, são desprezadas em troca de uma suposta formação para adequação à "era tecnológica".

Portanto, o aprofundamento da chamada revolução técnico-científica e o reabastecimento das possibilidades tecnológicas resultantes dela, constituem o marco da transformação radical da ciência em mercadoria, cada vez mais ajustada às necessidades imediatas do capital. A educação, nessa nova configuração, como qualquer outro complexo social, passa a ser reorientada sob os impulsos das demandas do mercado capitalista.

As prováveis contradições em relação à tecnologia já eram apontadas por Marx (1978, p. 81): "sabemos que as novas forças da sociedade têm unicamente necessidade, para adquirir um efeito benéfico, de homens novos, que a dominarão - refiro-me aos operários". Diante do avanço da indústria moderna, faz-se necessário indagar criticamente se nessa contradição encontra-se o potencial emancipador dos avanços tecnológicos. Seria ingenuidade acreditar que tal quadro contraditório, por si só, geraria um movimento mecânico de superação. Isso seria como acreditar que a tecnologia é emancipadora em si mesma.

Para refutar esse pensamento ingênuo que se espalha pelos documentos oficiais, bem como entre alguns intelectuais, empresários, jornalistas, entre muitos outros segmentos, foi fundamental refletir sobre o maniqueísmo encalçado no primado da técnica e da tecnologia. A partir da aproximação com as pesquisas de Álvaro Vieira Pinto, ficou notório que a tecnologia como filosofia da técnica precisa ser baseada no entendimento das relações entre o homem e a natureza contextualizada, por sua vez, no modo de produção da sociedade e fundamentada no horizonte do materialismo dialético para uma análise de base sólida e responsável. Também foi possível, a partir deste autor, compreender a forma como a categorização da técnica e da tecnologia têm produzido uma amarração de fatores que servem de sustentação ao apanhado de concepções teóricas ludibriantes que encobrem o cenário de profunda barbárie social.

Apoiamo-nos, mais uma vez, em Vieira Pinto (2008) para inferir que a técnica não deve ser endeusada nem repudiada, pois tais misticismos conceituais pretendem, no fim das contas, encobrir as consequências basilares dos problemas capitalistas, 
além de estruturarem o arcabouço ideológico responsável por subsumir o cotidiano do trabalhador frente ao emaranhado ideológico que exulta e justifica a deturpação dessas duas categorias.

Desta forma, a tecnologia deveria ser considerada patrimônio da humanidade. Tal categoria sozinha não guarda o cerne da transformação da sociedade, embora seja uma das condições para a evolução humana, para a emancipação plena da humanidade. Logo, as máquinas construídas pelo trabalho humano não têm o poder de promover a atual precarização social agudizada pela era do capital. As máquinas não guardam uma carga moral. Não são boas ou más por si sós. A natureza do problema encontra-se no emprego que se faz da tecnologia e, principalmente, na aplicação das possibilidades que o maquinário coloca a serviço do capital: garantir o acúmulo do lucro para uma privilegiada parcela da população mundial.

Observa-se uma ampla utilização das categorias técnica e tecnologia nos documentos oficiais, sobretudo aqueles voltados à EP e ao EM, que, por seu turno, definem e estabelecem as políticas curriculares para o sistema educacional brasileiro. $O$ discurso das políticas públicas estatais entende o desenvolvimento dessas duas categorias de maneira autônoma. Esse equívoco, como demostrado na exposição, é operado pelo fato de que os elaboradores de tais documentos acabam por desprezar as experiências sociais e, sobretudo, relegam a segundo plano a centralidade do trabalho para o desenvolvimento da vida humana, o que os leva a supor a existência de neutralidade na técnica e na tecnologia em relação às contradições sociais.

Para essa ' o caráter mistificador implantado em torno desses conceitos torna-se, desse modo, uma peça fundamental para justificar as políticas educacionais que estimam a EP como a principal alternativa aos filhos dos trabalhadores. O caminho percorrido procurou desconstruir a idolatria vinculada à suposta "era tecnológica", bem como o arcabouço ideológico que a reveste, evidenciando, outrossim, as refinadas táticas de controle dos grandes conglomerados capitalistas.

A mistificação da técnica e, em especial, da tecnologia, bastante difundida na consciência das pessoas, permeia o debate na sociedade a respeito da profissionalização da educação como proposta viável para o emblemático contexto educacional brasileiro. Discursos empresariais, governamentais e até de determinados intelectuais prometem a chamada empregabilidade a partir da formação técnica. Entretanto, não é dito que dedicar determinada condição de escolaridade profissional não é garantia de condições de disputar um emprego, minimamente estável, num mercado de trabalho cada vez mais volátil em vista dos avanços tecnológicos e condições econômico-estruturais da atualidade.

Essas palavras finais não esgotam a discussão, mas, em larga medida, procuram desmistificar o discurso operado pelas classes dirigentes, bem como desvelar os intentos dos reformadores empresariais e o discurso da profissionalização, sinalizando que o destino reservado aos jovens trabalhadores-estudantes não é outro, senão o 
de ser "elevado" à condição de mão-de-obra dócil, barata e acessível, presa fácil à avidez do capital. Eis o legado da supressão da criticidade.

\section{Referências}

BRAVERMAN, Harry. Trabalho e capital monopolista: a degradação do trabalho no século XX. Rio de Janeiro: Zahar Editores, 1980.

BRASIL. Decreto $n^{\circ} 2.208$ de 17 de abril de 1997. Regulamenta o $\S 2^{\circ}$ do art. 36 e os arts. 39 a 42 da Lei $n^{\circ}$ 9.394, de 20 de dezembro de 1996, que estabelece as diretrizes e bases da educação nacional. Diário oficial da União, Brasília, DF, 18 de abril de 1997, p. 7760.

Ministério da Educação. Diretrizes Curriculares Nacionais para o Ensino Médio. Brasília: MEC, 1998.

Decreto $n^{\circ} 5.154$, de 23 de julho de 2004. Regulamenta o § $2^{\circ}$ o art. 36 e os arts. 39 a. 41 da Lei $n^{\circ}$ 9.394. Disponível em: http://www. planalto.gov.br/ccivil_03/_ato2004-2006/2004/decreto/d5154.htm Acesso: 19 de jul. 2014.

Profissional de Nível Técnico. Brasília, MEC, 2000.

Diretrizes Curriculares Nacionais para a Educação Conselho Nacional de Educação. Diretrizes curriculares. Brasília, 2002. Disponível em <: http://www.unifenas.br/radiologia/resol_cne3. pdf >. Acesso em: 21/03/2012.

. Decreto $n^{\circ} 6.094$, de 24 de abril de 2007. Dispõe sobre a implementação do Plano de Metas Compromisso Todos pela Educação, pela União Federal, em regime de colaboração com Municípios, Distrito Federal e Estados. Disponível em <http://www.planalto.gov.br/ccivil_03/_ato2007-2010/2007/ decreto/d6094.htm. $>$ Acesso em: 20/07/2014.

profissional e tecnológica. Brasília, 2004. Disponível em: <http://www. educacaoprofissional. sct.ce.gov.br/>. Acesso em: 21/03/2005.

FREITAS, Luiz Carlos de. Os reformadores empresariais da educação: a consolidação do neotecnicismo no Brasil. $10^{\circ}$ Encontro de Pesquisa em Educação 
da Região Sudeste. Rio de Janeiro, julho de 2011.

- "Agenda dos reformadores educacionais pode destruir a educação pública no Brasil". Revista Adusp, São Paulo, out. 2012. Disponível em: <http:// www.adusp.org.br/files/revistas/53/mat01.pdf>.

FRIGOTTO, Gaudêncio; CIAVATTA, M.; RAMOS, M. A política de educação profissional no governo Lula: um percurso histórico controvertido. Educação e Sociedade, Campinas, vol. 26, n. 92, p. 1087-1113, out. 2005.

QUARTIERO, Elisa Maria; LUNARDI, Geovana Mendonça; BIANCHETTI, Lucídio. Técnica e tecnologia: aspectos conceituais e implicações educacionais. IN: MOLL, Jaqueline et al. (Org.). Educação profissional e tecnológica no Brasil contemporâneo: desafios, tensões e possibilidades. Porto Alegre: Artmed, 2010.

RAMOS, Marise. Ensino médio integrado: ciência, trabalho e cultura na relação entre educação profissional e educação básica. In: MOLL, Jaqueline et al. (Org.). Educação profissional e tecnológica no Brasil contemporâneo: desafios, tensões e possibilidades. Porto Alegre: Artmed, 2010.

ROMERO, Daniel. Marx e a técnica - um estudo dos manuscritos de 1861-1863, São Paulo: Expressão Popular, 2005.

RÜDIGER, Francisco. Marxismo e a antropologia da técnica. IN: Revista Contemporânea, UERJ, Edição 05, vol.3, n. 2, jul/dez 2005.

SANTOS, Deribaldo. Graduação tecnológica no Brasil: crítica à expansão do ensino superior não universitário. Curitiba: CRV, 2012.

Concepções epistemológicas e onto-históricas da técnica e da tecnologia: um debate no legado de Álvaro Vieira Pinto. In: SANTOS, Deribaldo et al. (Org.). Educação pública, formação profissional e crise do capitalismo contemporâneo. Fortaleza: EdUECE, 2013.

; JIMENEZ, Susana; MENDES SEGUNDO, Maria das Dores. O Ideário Educacional competente no contexto da crise estrutural do capital. Cadernos de Pesquisa em Educação PPGE-UFES, v.17, p.9 - 33, 2011. ISSN: 1519-4507.

; FREITAS, Maria C. C.; FARIAS, Aracelia C. Ensino médio integrado no estado do Ceará: o "Caminho das pedras" do empreendedorismo para a escola pública. In: Revista Expressão Católica, v. 1, n. 2, p. 58-68, jul./dez. 2013.

SAVIANI, Dermeval. Escola e democracia. 36. Ed. - Campinas: Autores Associados, 2003. 
SOUSA JÚNIOR, Justino de. Marx e a crítica da educação: da expansão liberaldemocrática à crise regressivo-destrutiva do capital. Aparecida, SP: Ideias \& Letras, 2010.

VIEIRA PINTO, Álvaro. O conceito de tecnologia. Rio de Janeiro: Contraponto, 2008. Vol.1.

Recebido em março de 2017

Aceito em setembro de 2017

José Deribaldo Gomes dos Santos é Doutor em Educação Brasileira pela Universidade Federal do Ceará (UFC). Concluiu, em 2015, estágio pós-doutoral em Estética na Universidad Complutense de Madrid (UCM). É Professor Adjunto da Faculdade de Educação, Ciências e Letras do Sertão Central (FECLESC-UECE), atuando no Programa de Pós-Graduação em Educação (PPGE/UECE) e no Mestrado Acadêmico Intercampi em Educação e Ensino (MAIE/UECE). É pesquisador do Instituto de Estudos e Pesquisas do Movimento Operário (IMO-UECE) e do Laboratório de Pesquisas sobre Políticas Sociais do Sertão Central (Lapps-UECE). Desenvolve pesquisas nas áreas de Trabalho e Educação e Estética Marxista. Atua, principalmente, no exame da Educação Profissional e na Formação de Professores. Lidera o Grupo de Pesquisa Trabalho, Educação, Estética e Sociedade (GPTREES).Email:deribaldo.santos@uece.br

Ellen Cristine dos Santos Ribeiro é Mestra em Educação pelo Programa de PósGraduação em Educação (PPGE) da Universidade Estadual do Ceará (UECE). Especialista em Coordenação Pedagógica e Gestão Escolar (FA7). Pedagoga (UFC). Professora efetiva da Prefeitura Municipal de Fortaleza. Pesquisadora-colaboradora do Instituto de Estudos e Pesquisas do Movimento Operário (IMO) da Universidade Estadual do Ceará. Membro do grupo de pesquisa Trabalho, educação, estética e sociedade (GPTREES). Email:ellencristineribeiro@hotmail.com

Thiago Chaves Sabino é Mestre em Educação pelo Programa de Pós-Graduação em Educação (PPGE) da Universidade Estadual do Ceará (UECE). Graduado em Física pela Universidade Estadual do Ceará (UECE). Email:tcs54@hotmail.com 